\title{
Determination of the optimal mating age of colonised Glossina brevipalpis and Glossina austeni using walk-in field cages in South Africa
}

\author{
Chantel J. de Beer ${ }^{1,2^{*}}$ D, Gert J. Venter ${ }^{1}$ and Marc J. B. Vreysen ${ }^{3}$
}

\begin{abstract}
Background: For the control of Glossina brevipalpis and Glossina austeni that occur in South Africa an area-wide integrated pest management (AW-IPM) program with a sterile insect technique (SIT) component has been proposed. The quality of the released sterile male tsetse flies will greatly determine the success of the SIT component of the programme. Sterile males need to be able to compete with wild males immediately after their release in the affected area. The mating competitiveness can be affected by many factors including the optimal mating age of the fly which can have an impact on the timing of the release.
\end{abstract}

Methods: To assess the optimal mating age for G. brevipalpis and G. austeni, mating competitiveness studies were carried out in a walk-in field cage. First, the time of peak fly activity was determined by performing the experiment in the morning and then again in the afternoon. Thereafter, 3, 6 and 9-day-old male flies competed for 3-day-old virgin females.

Results: There were no significant differences in mating performance when the field cage experiments were done in the morning or in the afternoon. However, the mating latency was shorter in the afternoon than in the morning. For both species 9-day-old males mated significantly more often than 6 or 3-day-old males. Age did not affect the males' ability to transfer sperm, mating duration or the mating latency. All females that mated were inseminated.

Conclusions: Age did influence the mating competitiveness of $G$. brevipalpis and G. austeni and it is recommended that sterile males are not released before the age of 9 days. Keeping the male flies in the rearing facility for 8 days will have economic and logistic consequences for AW-IPM programmes that have a SIT component.

Keywords: Tsetse flies, Sterile insect technique, Optimal mating age, Walk-in field cage, Mating competitiveness

\section{Background}

Tsetse flies (Diptera: Glossinidae) are the vectors of the trypanosome parasites that cause African trypanosomosis, an important tropical disease affecting livestock (nagana) and humans (sleeping sickness) throughout sub-Saharan Africa [1]. Of the 31 species and subspecies present in Africa only Glossina brevipalpis and Glossina

\footnotetext{
*Correspondence: debeerc@arc.agric.za

${ }^{1}$ Agricultural Research Council-Onderstepoort Veterinary Institute Parasites, Vectors \& Vector-borne Diseases, Private Bag X 05, Onderstepoort 0110, South Africa

${ }^{2}$ Department of Zoology and Entomology, Faculty of Natural and Agricultural Sciences, University of the Free State, PO Box 339, Bloemfontein 9300, South Africa

Full list of author information is available at the end of the article
}

austeni occur presently in South Africa where they are responsible for the cyclical transmission of Trypanosoma brucei brucei, Trypanosoma congolense and Trypanosoma vivax, the causative agents of nagana [2-5].

The tsetse infested area $\left( \pm 16000 \mathrm{~km}^{2}\right)$ in South Africa is confined to the north-eastern part of KwaZulu-Natal Province. It stretches from the Mfolozi River $(-28.499639,32.40)$ in the south to the border of Mozambique $(-26.8692,32.8342)$ in the north, and from the Indian Ocean coast in the east to the iMfolozi Park $(-28.33416,31.691222)$ in the west [6]. The flies are mostly restricted to game reserves and rural farming areas near the reserves as these areas contain suitable vegetation and hosts [7]. The G. brevipalpis belt stretches from 
Ethiopia in northern East Africa to KwaZulu-Natal in South Africa, with infested areas in Somalia, Uganda, Kenya, Rwanda, Burundi, Tanzania, Malawi, Zambia, Zimbabwe and Mozambique [8]. Glossina austeni is more confined to the coastal areas of East Africa and its belt extends from Somalia into Kenya, Tanzania, Zimbabwe and Mozambique [8]. The G. brevipalpis and G. austeni populations in South Africa extending into Matutuini Province of southern Mozambique are geographically relatively isolated and represent the southernmost distribution of tsetse flies in Africa. Recently, surveys in Swaziland detected the presence of G. austeni in the Mlawula Game Reserve in the east of the country $[9,10]$.

Following the outbreak of nagana in KwaZulu-Natal in 1990, the Agricultural Research Council - Onderstepoort Veterinary Institute (ARC-OVI) was commissioned to develop a sustainable strategy that would resolve the tsetse and trypanosomosis problem in South Africa [7]. After the development of suitable trapping systems for the two species [6] and the collection of various base line data sets, a strategy was proposed that was based on area-wide integrated pest management (AW-IPM) principles [3, 11]. The proposed strategy included the suppression of the G. brevipalpis and G. austeni populations with the sequential aerosol technique [3], followed by the releases of sterile males [12] to eradicate all potential relic pockets [3].

The sterile insect technique (SIT) involves the colonisation and mass-rearing of the target species for the sterilisation of the males using ionising radiation. In order to compete with the wild males, sterile males need to be released in sufficient numbers and on a sustainable basis to achieve appropriate sterile to wild male overflooding ratios [13]. Because the sperm of the released males is sterile due to the induction of numerous dominant lethal mutations [13], the mating between sterile males and fertile virgin wild females results in no offspring [14]. When adequate proportions of the wild females mate with sterile males, there will be a lower population replacement rate, which will lead to a reduction in the density of the wild target insect population, leading eventually to potential eradication [14]. The slow reproduction rate of tsetse flies [15] makes the release of sterile males very amenable for the management of tsetse fly populations $[11,16]$.

The successful implementation of an AW-IPM programme with an SIT component depends on a number of prerequisites [11]; the biological quality and sexual competitiveness of the sterile males being amongst the more important ones [17]. The colony reared and released sterile males must be able to compete successfully with the wild males for mating opportunities with the wild virgin females [18]. Releasing low quality sterile males will necessitate higher release rates, require more funding and might prolong the duration of the programme potentially leading to programme failure [17]. One of the factors that can influence mating success of released sterile male tsetse is the males' age: competitiveness of Glossina fuscipes fuscipes, Glossina palpalis palpalis, Glossina palpalis gambiensis, and Glossina pallidipes was significantly influenced by the age of the sterilised males [19-22].

Determination of the optimal mating age of colonised tsetse flies under natural conditions in the field will be challenging, costly, and the results might be influenced by several environmental, climatic and ecological parameters which cannot be controlled. In the past, large walk-in field cages have been successfully used as a suitable surrogate for open field studies to conduct mating compatibility, mating competitiveness and other behavioural studies for fruit flies, tsetse flies and Lepidoptera [21, 23-25]. Similar field cages have successfully been used to determine the optimal mating age for G. f. fuscipes, G. p. palpalis and G. p. gambiensis [19].

The SIT has never been used against G. brevipalpis and no data are available on the optimal mating age of this species. The eradication campaign of G. austeni on Unguja Island, Zanzibar used sterile male flies that were mass-reared at the Tsetse and Trypanosomiasis Research Institute (TTRI) (now named Vector \& Vector-Borne Diseases Research Institute) Tanga, United Republic of Tanzania, and released on the island when 3-5 days of age. No studies were, however, carried out to assess the optimal mating age of G. austeni.

In preparation of a potential AW-IPM programme in South Africa that could include a SIT component, this study was carried out at the ARC-OVI to determine the optimal mating age of colonised G. brevipalpis and $G$. austeni using walk-in field cages.

\section{Methods}

\section{Colony tsetse flies}

Laboratory colonies of G. brevipalpis and G. austeni were established in 2002 at the ARC-OVI in Pretoria, South Africa using seed material from the TTRI and the Entomology Unit of the FAO/IAEA's Laboratories in Seibersdorf, Austria (now called the FAO/IAEA Insect Pest Control Laboratory), respectively. The colony flies were maintained under standard colony conditions $\left(23-24{ }^{\circ} \mathrm{C}\right.$, 75-80 \% RH and subdued/indirect lighting, $12 \mathrm{~h}$ light/12 h dark) $[26,27]$. Flies were offered a blood meal daily, consisting of abattoir collected defibrinated bovine blood using an artificial in vitro membrane feeding system [26, 27].

\section{Walk-in field cage and environmental conditions}

Comparative assessment of the mating performance of G. brevipalpis and G. austeni was conducted separately in large walk-in field cages under "near-natural" conditions [21, 28]. The cylindrical field cages $(\varnothing 2.9 \mathrm{~m} \mathrm{x}$ 
$2.0 \mathrm{~m}$ ) were made of polyester netting with a flat floor and ceiling and a $1.5 \mathrm{~m}$ potted weeping boer-bean Schotia brachypetala tree was placed in the middle of the cages during experiments. A zip from top to bottom sealed the entrance of the cages. The field cages were deployed in a small forest of approximately $15 \times 70 \mathrm{~m}$, consisting of a lane of century old chir pines (Pinus roxburghii) on one side and water berry trees (Syzygium cordatum) on the other. The forest also contained two large karee trees (Searsia lancea) that reduced the natural light intensity and numerous undergrowth (below $3 \mathrm{~m}$ ) of a variety of tree species; Hyphaene coriacea, Strelitzia nicolai, Ziziphus mucronata, Cussonia spicata, Syringa persica, Ligustrum lucidum, Melia azedarach, Dracena aletriformis and Jacaranda spp. The shrub and herb foliage layer (below $0.5 \mathrm{~m}$ ) consisted of Cyperus rotundus, Asparagus densiflorus, Tradescantia albiflora, Alpinia spp. as well as Hedera helix growing on the pine trees. The forest floor had a thick carpet of leaf litter and pine needles. Compared to the surroundings, the forest was a cool, humid area with low natural light intensity.

Throughout the experiment, temperature and relative humidity were recorded every 10 min using a DS1923F5\# Hygrochron iButton data logger. Light intensity was recorded every $15 \mathrm{~min}$ at the top and the bottom of the cage and at the tree level using a Major Tech MT940 light meter.

To determine the optimal mating age and time of peak mating activity 30 (3-day-old) female flies of either G. brevipalpis or G. austeni were released in the middle of the cage $5 \mathrm{~min}$ before releasing 90 male flies of the same species, giving a male female ratio of 3:1. An observer remained inside the cages for the entire 3-h duration of the experiment. Movements of the observer were kept to a minimum. The time of mating was recorded to determine mating latency, the mating pairs collected individually into small vials, and duration of the mating observed. Although no direct adverse effect on mating behaviour was observed when mating pairs were collected, the potential influence of this action on mating behaviour cannot be ruled out. To minimise this effect mating pairs were collected similarly in all experiments. These mating pairs were not replaced in the field cages.

The mated females were dissected the following day (flies were immobilised at $-5{ }^{\circ} \mathrm{C}$ before dissection) to determine insemination rate and spermathecal value [26, 27]. The spermathecae were removed and spermathecal fill was estimated by microscopic examination, they were scored as, empty (0), quarter full (0.25), half full (0.5), three quarter full (0.75) and full (1) [29]. Female flies that did not mate were dissected to confirm their virginity. All flies remaining in the cages at the end of the experiments were collected and returned to the colony. Glossina brevipalpis and $G$. austeni were evaluated separately.

\section{Time of peak mating activity}

In an initial set of experiments, the time of day at which the flies showed a peak in mating performance was determined. The performance of 9-day-old male flies with 3-day-old virgin females at a males:females ratio of 3:1 was assessed in the morning (9:00-12:00 h) and again in the afternoon (13:00-16:00 h). The experiment was replicated five times for both species in a two week period in March 2012.

\section{Optimal mating age}

The optimal mating age of males was assessed using walk-in field cages. Three-, 6- and 9-day-old male flies (30 males of each age) competed for 30 three-day-old virgin females of the same species as the males, giving a sex ratio of 3:1 (90 males: 30 females). To discriminate between the different male age groups, the flies were marked using a dot of different colours of polymer paint on the notum [21]. The males were marked $24 \mathrm{~h}$ before being released in the field cage experiments. The experiments with G. brevipalpis were carried out in March 2012 and those with G. austeni in March 2013.

\section{Mating competitiveness indicators}

The propensity of mating (PM), the relative mating index (RMI) and relative mating performance (RMP) were the mating indices used to assess the mating performance of the males in the various treatments. Propensity of mating (PM) was defined as the overall proportion of released females that mated. Relative mating index (RMI) was defined as the number of pairs of one treatment group as a proportion of the total number of matings [21]. Relative mating performance (RMP) was defined as the difference between the numbers of matings of two treatments of males as a proportion of the total number of matings [21]. In addition, the mating latency time, mating duration, insemination rate and the spermatheca fill of each mated female were determined.

\section{Data analysis}

All data were analysed using the statistical software GraphPad Instat [30]. For the time of peak mating activity, differences in the overall proportions were analysed with Chi-square $(x 2)$ analysis with the Yate's continuity correction. The $p$ value was two-sided and a relative risk, p1-p2 was also determined. Additionally an unpaired test was used to differentiate between the mating latency, mating duration and spermathecal fill means (Two- tail $p$ value $<$ 0.05 was considered as significant). Where the data passed the normality test, standard (parametric) methods were used with Welch correction. If the data was not normally distributed a nonparametric method (Mann-Whitney test) was used. 
For the optimal mating age determination experiments a one-way analysis of variance (ANOVA) was used to differentiate between the relative mating index, mating latency, mating duration and spermathecal fill means ( $p$ value $<0.05$ was considered as significant). Where the data passed the normality test, standard (parametric) methods were used and the Tukey's test was applied. If the data was not normally distributed the nonparametric Kruskal-Wallis test was used.

\section{Results}

\section{Environmental conditions}

All field cage experiments were conducted outdoors in a small forest at the ARC-OVI. During the ten replicates (five for each species) conducted in the morning the mean temperature gradually increased from $21.4 \pm 1.4{ }^{\circ} \mathrm{C}$ at the onset of the experiments $(9: 00 \mathrm{~h})$ to $25.0 \pm 2.8^{\circ} \mathrm{C}$ at the end (12:00 h) (Fig. 1i). The mean temperature in the field cages during these ten replicates was $24.4 \pm$ $2.4{ }^{\circ} \mathrm{C}$. The increase in temperature was accompanied by a steady decrease in relative humidity (Fig. 1ii). The $\mathrm{RH}$ decreased from an average of $68.0 \pm 7.3 \%$ to $52.3 \pm$ $13.0 \%$, the mean being $58.6 \pm 11.0 \%$. During the ten (five for each species) replicates conducted in the afternoon both the temperature and relative humidity were more stable. The temperature ranged from $27.6 \pm 1.3{ }^{\circ} \mathrm{C}$ to $29.0 \pm 2.0{ }^{\circ} \mathrm{C}$, the mean being $28.6 \pm 2.0{ }^{\circ} \mathrm{C}$. The relative humidity ranged from $37.9 \pm 7.8 \%$ to $46.5 \pm 6.8 \%$, the mean being $41.1 \pm 4.3 \%$. The light intensity at the top and bottom of the cage as well as at the potted plant was in general higher in the afternoon $(433.0 \pm 271.6 \mathrm{Lx})$ than in the morning $(301.9 \pm 194.5 \mathrm{Lx})$. During the morning the light intensity was higher at the top $(351.0 \pm 102.7$ Lx) of the cage as compared to the other areas. During the trials in the afternoon the difference in light intensity at the top $(432.3 \pm 155.8 \mathrm{Lx})$ and bottom $(510.2 \pm 387.1 \mathrm{Lx})$ of the cage was less pronounced.

\section{Activity in field cage}

After release, males and females of both species dispersed immediately with most of the G. brevipalpis (males and females) settling in the top half of the cage and finding a resting site on the black band that connects the top and vertical netted panels of the cage. In contrast, male and female G. austeni settled mostly in the bottom half of the cage, once again favouring the black band that connects the bottom and vertical netted panels of the cage. No other differences were observed in the behaviour of G. austeni and G. brevipalpis towards the field cage environment.

For both species most of the flies settled in the more shaded areas of the cage and only a few flies settled on the tree. Some flies remained immobile after being released until being recaptured and no mating was observed for these flies. After male release, there were immediate matings, the overall minimum mating latency time was $2 \mathrm{~min}$. Occasionally more than one male was trying to mate with the same female. Some attempted matings by the males were met with clear rejection from the female.

\section{Time of peak mating activity}

The propensity of mating in the morning was 0.70 and 0.49 for G. brevipalpis and G. austeni, respectively. This was not significantly higher than that of 0.66 for G. brevipalpis ( $p=$ $0.624)$ and 0.59 for $G$. austeni $(p=0.151)$ as determined in the afternoon (Table 1). The average mating latency was longer in the morning than in the afternoon for $G$. brevipalpis $(p=0.007)$ and G. austeni $(p=0.001)$ and was significantly different for both species (Table 1 ). Figure 2 indicates that for both species, more flies mated in the first hour of the experiment in the afternoon as compared with the morning experiment.

The G. brevipalpis couples mated on average for $174.21 \pm 0.06 \mathrm{~min}$ in the morning and for $165.13 \pm$ $0.06 \mathrm{~min}$ in the afternoon which was not significantly different $(p=0.558)$. For $G$. austeni the average mating duration in the morning $(204.50 \pm 0.06 \mathrm{~min})$ was significant longer than in the afternoon $(138.63 \pm 0.04 \mathrm{~min})$ $(p<0.001)$. The mean spermathecal value for $G$. brevipalpis in the morning $(0.75 \pm 0.20)$ was slightly lower than in the afternoon $(0.86 \pm 0.10)(p=0.002)$, the overall insemination rate was above $99 \%$ (Table 1 ). The insemination rate for $G$. austeni was above $94 \%$. The mean spermathecal value of G. austeni was significantly different $(p=0.003)$ in the morning $(0.80 \pm 0.20)$ than in the afternoon $(0.68 \pm 0.30)$ (Table 1).

\section{Optimal age determination}

The overall proportions of released females that mated (propensity of mating) for the optimal mating age assessment was 0.46 for $G$. brevipalpis and 0.43 for $G$. austeni (Table 1). The Relative mating performance for G. brevipalpis and G. austeni was 0.84 and 0.54 respectively and both in favour of 9-day-old males. The mean relative mating index (Table 1) for 9-day-old males $(0.68 \pm 0.23$ for $G$. brevipalpis and $0.54 \pm 0.12$ for $G$. austeni) was significantly higher than that of 6-day-old $(0.25 \pm 0.20, p<0.010$ for G. brevipalpis and $0.30 \pm$ $0.16, p<0.010$ for $G$. austeni) and 3-day-old (0.06 \pm 0.06, $p<0.001$ for $G$. brevipalpis and $0.17 \pm 0.14, p<0.001$ for G. austeni) males for both species (Fig. 3). The relative mating index was not significantly different $(p>0.050)$ between 6-day and 3-day-old males for both species (Fig. 3).

For G. brevipalpis the mean mating latency, ranging from $40.33 \pm 0.05$ for 3 -day-old males to $56.38 \pm 0.03$ for 6 -day-old males was not significantly different $(p=$ 0.735 ) (Table 1 ). Similarly mean mating duration ranging 


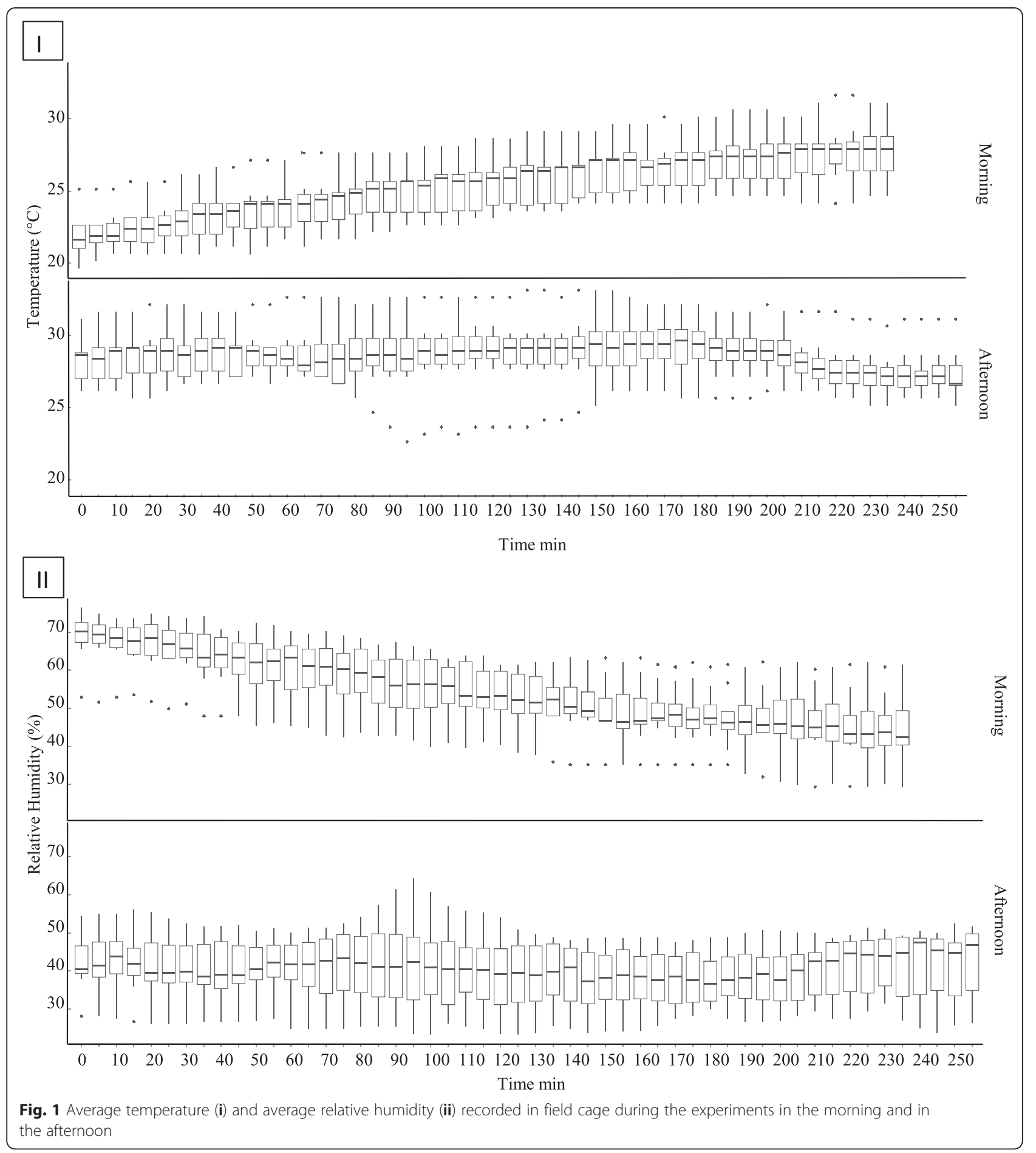

from $152.24 \pm 0.04$ for 6-day-old males to $193.48 \pm$ 0.04 for 9-day-old males was not significantly different $(p=0.212)$ (Table 1$)$. There were, however, significant differences in the mean spermathecal fill between age groups $(p=0.008)$. The mean spermathecal fill in 3 -day-old-males $(0.25 \pm 0.30)$ was significantly different from that of 6-day-old $(0.79 \pm$
$0.30, p<0.010)$ and 9-day-old $(0.74 \pm 0.30, p<0.050)$ males.

Similar for G. austeni the mean mating latency (ranging from $84.07 \pm 0.04$ for 6 -day-old to $103.56 \pm 0.05$ for 3 -day-old males) and mean mating duration (ranging from $126.80 \pm 0.04$ for 3 -day-old to $144.80 \pm 0.06$ for 9 day-old males) was not significantly different ( $p=0.444$, 
Table 1 Summary of various mating parameters for Glossina brevipalpis and G. austeni in the field cage for accessing the time of peak mating activity and optimal mating age

\begin{tabular}{|c|c|c|c|c|c|c|c|c|}
\hline & $\begin{array}{l}\text { Possible } \\
\text { pairs }\end{array}$ & $\begin{array}{l}\text { Actual } \\
\text { mated }\end{array}$ & $\begin{array}{l}\text { Overall proportion } \\
\text { (PM) }\end{array}$ & $\begin{array}{l}\text { Relative mating } \\
\text { index (RMl } \pm \mathrm{SD} \text { ) }\end{array}$ & $\begin{array}{l}\text { Mating latency } \\
\text { time }(\min \pm S D)\end{array}$ & $\begin{array}{l}\text { Mating duration } \\
(\min \pm S D)\end{array}$ & $\begin{array}{l}\text { Mean spermathecal } \\
\text { value }\end{array}$ & $\begin{array}{l}\text { Insemination } \\
\text { rate }\end{array}$ \\
\hline \multicolumn{9}{|c|}{ G. brevipalpis } \\
\hline $\begin{array}{l}\text { Fly activity } \\
\text { morning }\end{array}$ & 90 & 63 & 0.70 & - & $73.15 \pm 0.04$ & $174.21 \pm 0.06$ & $0.75 \pm 0.20$ & 1.00 \\
\hline $\begin{array}{l}\text { Fly activity } \\
\text { afternoon }\end{array}$ & 120 & 79 & 0.66 & - & $47.16 \pm 0.03$ & $165.13 \pm 0.06$ & $0.86 \pm 0.12$ & 0.99 \\
\hline Male age & 210 & 97 & 0.46 & - & $54.40 \pm 0.03$ & $173.20 \pm 0.03$ & $0.72 \pm 0.31$ & 0.94 \\
\hline 9 days & - & 67 & - & $0.68 \pm 0.23$ & $55.03 \pm 0.03$ & $193.48 \pm 0.04$ & $0.74 \pm 0.28$ & 0.94 \\
\hline 6 days & - & 24 & - & $0.25 \pm 0.20$ & $56.38 \pm 0.03$ & $152.24 \pm 0.04$ & $0.79 \pm 0.28$ & 0.96 \\
\hline 3 days & - & 6 & - & $0.06 \pm 0.06$ & $40.33 \pm 0.05$ & $176.00 \pm 0.04$ & $0.25 \pm 0.35$ & 0.33 \\
\hline \multicolumn{9}{|l|}{ G. austeni } \\
\hline $\begin{array}{l}\text { Fly activity } \\
\text { morning }\end{array}$ & 120 & 59 & 0.49 & - & $94.33 \pm 0.04$ & $204.50 \pm 0.06$ & $0.80 \pm 0.20$ & 0.98 \\
\hline $\begin{array}{l}\text { Fly activity } \\
\text { afternoon }\end{array}$ & 150 & 88 & 0.59 & - & $58.36 \pm 0.04$ & $138.63 \pm 0.04$ & $0.68 \pm 0.25$ & 0.94 \\
\hline Male age & 360 & 153 & 0.43 & - & $94.30 \pm 0.05$ & $137.40 \pm 0.05$ & $0.57 \pm 0.30$ & 0.93 \\
\hline 9 days & - & 83 & - & $0.54 \pm 0.12$ & $97.10 \pm 0.05$ & $144.80 \pm 0.06$ & $0.61 \pm 0.30$ & 0.95 \\
\hline 6 days & - & 45 & - & $0.30 \pm 0.16$ & $84.07 \pm 0.04$ & $139.20 \pm 0.04$ & $0.54 \pm 0.25$ & 0.96 \\
\hline 3 days & - & 25 & - & $0.17 \pm 0.14$ & $103.56 \pm 0.05$ & $126.80 \pm 0.04$ & $0.51 \pm 0.34$ & 0.80 \\
\hline
\end{tabular}

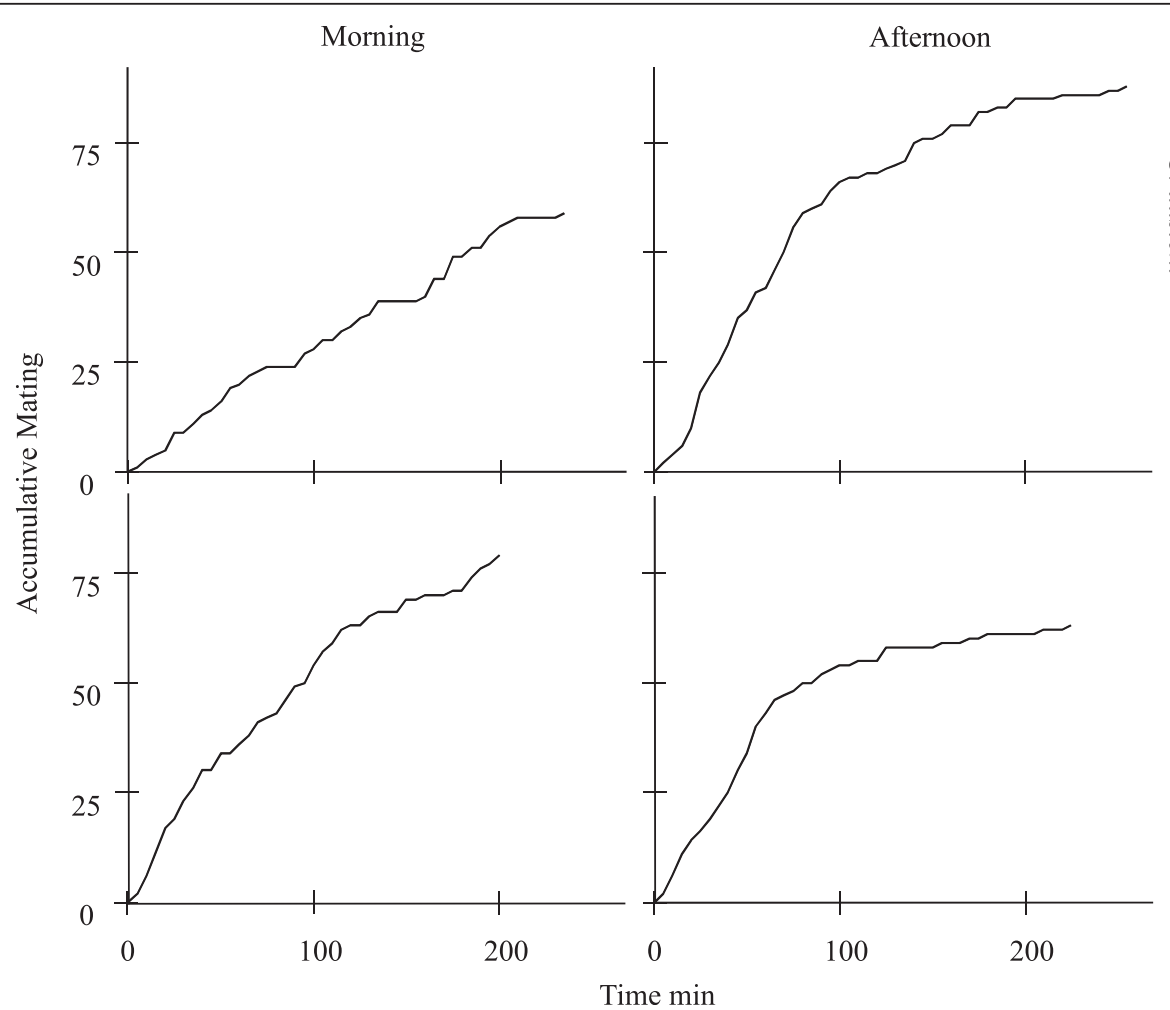

$\Omega$
0
0
0
0

व.

Fig. 2 Accumulative mating for Glossina austeni and G. brevipalpis in the morning and in the afternoon 


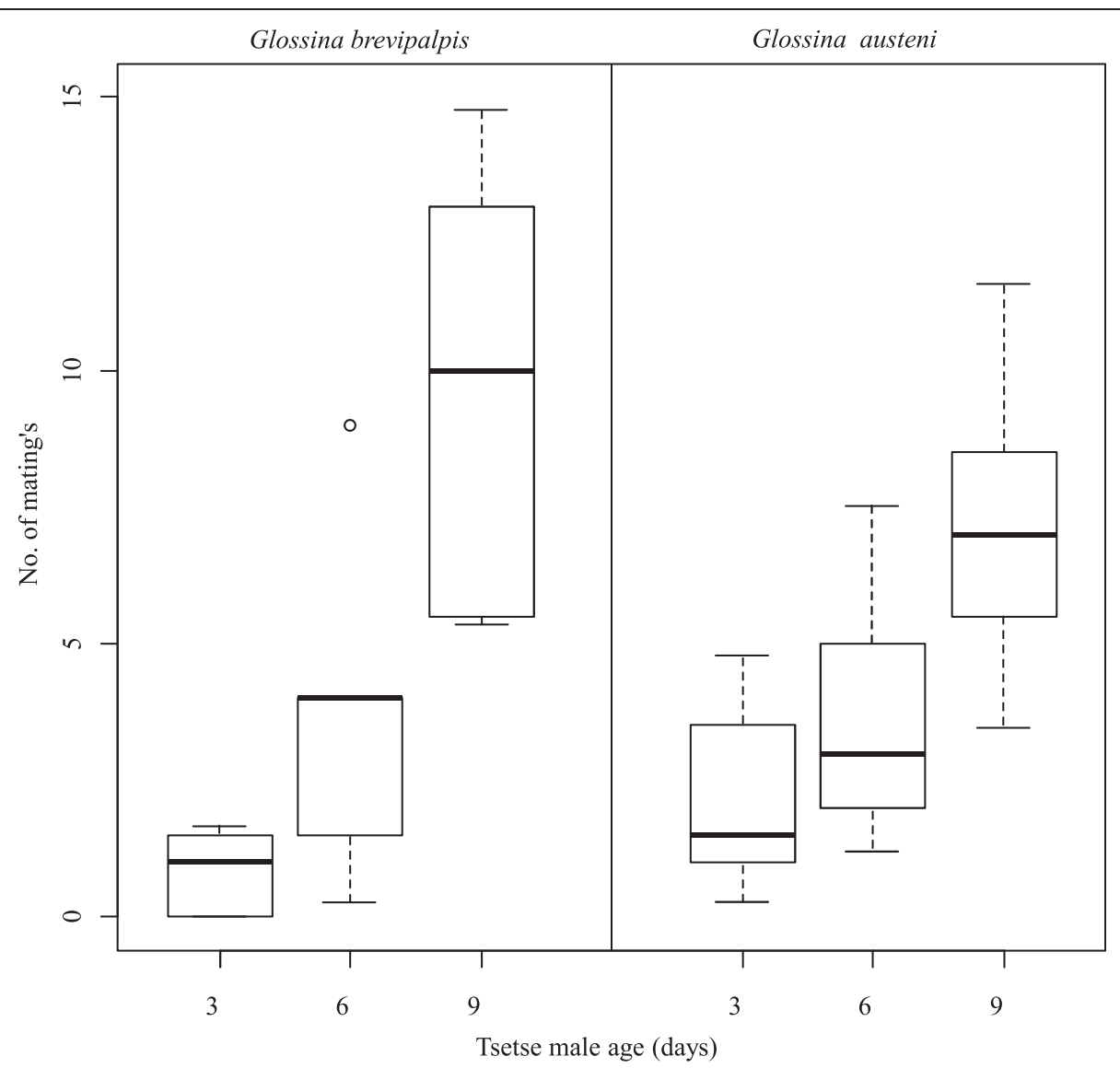

Fig. 3 Number of males from the age groups that mated with the females in the field cage

$p=0.738$, respectively) (Table 1 ). In contrast to G. brevipalpis no significant difference $(p=0.372)$ was observed for the different age groups (Table 1).

For G. brevipalpis, age did affect the insemination rate. The insemination rate for females mated with 3-day-old males was only 0.33 compare for 6-day-old (0.96) or 9day-old males (0.94) (Table 1). For G. austeni the insemination rate ranged from 0.80 (3-day-old males) to 0.96 (6-day-old males) (Table 1).

\section{Discussion}

AW-IPM programmes that include an SIT component can only be successful if the released sterile male insects are competitive with their native counterparts [17, 31]. Assessment of the mating competitiveness of the produced and released insects is therefore a prerequisite before any operational SIT programme can be initiated [11]. There are various biological (rate of development, temperature adaptation, circadian rhythm, flight capability, optimal mating age, weight, etc.) and operational (insect collection techniques, handling, radiation, release technologies, etc.) attributes that may affect the biological quality of the produced and released insect [32]. Quantification of the impact of each of these attributes on the released insects' competitiveness is paramount to enable the development of procedures to mitigate any potential negative effects.

The results of this study indicate that the age of both G. austeni and G. brevipalpis male flies was significantly correlated with their mating performance as indicated by the RMI. Nine-day-old males were significantly more successful in securing a female for mating than 6-or 3day-old males. These results are in agreement with data obtained for G. f. fuscipes and G. p. palpalis [19]. Although older G. brevipalpis and G. austeni males were more competitive to secure a mate in the field cages, the age of the males did not influence mating duration or insemination ability. This confirms data of Malele and Parker [33] who observed that G. austeni males that had mated on the day after emergence could successfully inseminate females of the same age in small laboratory cages. Our data on the optimal mating age indicate that the propensity of mating of both G. austeni and $G$. brevipalpis can possibly be improved by releasing older sterile males. However, this would require keeping the males longer in the rearing facility, which unavoidably will increase the maintenance and production costs. This protocol would require more blood meals to be offered 
to the sterile males before their release, more labour to absorb the increased handling needs and larger facilities to stockpile the flies before release. Some male thephritid fruit flies take several weeks to reach sexual maturity, and exposure to juvenile hormone mimics significantly accelerated the rate of sexual maturity in some of them [34]. In addition, adding certain supplements to the diet (e.g. protein) of the melon fly Bactrocera cucurbitae [35] or exposure of species such as Bactrocera carambolae to methyl eugenol significantly increased the mating performance of the males [36]. It would therefore be very useful to assess whether there are factors that can be implemented to shorten the period before the optimal mating age for G. austeni and G. brevipalpis is reached.

In the majority of previous control programmes that included a SIT component, the sterile males used for release were rather young, i.e. sterile male G. austeni were 4-7 days old when released on Unguja Island, Zanzibar [37], sterile male G. $p$. palpalis were 3-5 days old when released in the Lafia area of Nigeria [38], and sterile male Glossina tachinoides were 2-10 days old when released in a pilot trial in Chad [39]. Using younger males avoided losses in the rearing facility due to mortality, and was cost effective in terms of space and labour. These release protocols were in addition driven by mating observations in small laboratory cages that indicated that male mating and insemination was possible when the male flies were less than 5 days old [33], although other researchers used males that were between 5-8 days old for various experiments [22, 40, 41]. In these operational programmes, sterile males were offered at least two blood meals that contained a trypanocidal drug (e.g. $12.5 \mathrm{mg}$ of Samorin. $\mathrm{L}^{-1}$ blood in the programme on Unguja [37]) before release that significantly reduced the risk of transmitting the disease trypanosomes.

An entirely different release strategy was used in the SIT trial against Glossina morsitans morsitans in the Tanga area, Tanzania, in the 1970's. Here sterile males were released as pupae from fixed release stations and emerging males were consequently teneral and had to look for a blood meal quickly to build up energy reserves [42]. A drawback of this method was that the males were exposed to potential predation before reaching sexual maturity and could become potential vectors of the disease. Despite this, the programme was quite successful and releasing the male pupae at a rate of $135 \mathrm{~km}^{-2}$ resulted in a sterile male wild male overflooding ratio of 1.2:1 which, despite being low, maintained the indigenous wild fly population at the $80-95 \%$ reduction level obtained after the initial insecticide application [43].

In our experiments, there was no significant difference in male activity and mating performance in the morning and the afternoon for both species, indicating that field cage experiments could be conducted in either the morning or afternoon at the ARC-OVI. The environmental conditions were more variable in the morning with a lower average temperature and a higher average relative humidity in contrast to the afternoon when conditions were more stable (but temperatures were on average higher and relative humidity lower). The afternoon time 12:00 to 15:00 was selected for all other field cage experiments to cover the afternoon activity peak of G. brevipalpis.

The equal mating performance of both G. brevipalpis and G. austeni in the afternoon and the morning seems to be conforming to the diurnal activity patterns as observed for G. brevipalpis in South Africa but not for G. austeni. These studies indicated a bimodal activity pattern for G. brevipalpis i.e. flies were active early in the morning from dawn until a period after sunrise and then late in the afternoon, whereas G. austeni showed a more pronounced unimodal activity pattern and flies were active from early morning till late afternoon [44]. The G. austeni data from South Africa were in contrast with those obtained by Owaga, Okelo \& Chaudhury [45], who observed two G. austeni activity peaks in Kenya, one between $9.00 \mathrm{~h}$ to $10.00 \mathrm{~h}$ and a second between $14.00 \mathrm{~h}$ and $17.00 \mathrm{~h}$. A study on Unguja Island showed temporal variation in the activity pattern of G. austeni, i.e. two activity peaks were observed in the rainy season (June/July), with the larger one around noon, and a second, smaller activity peak around $16.00 \mathrm{~h}$. During the dryer and warmer period of the year (October-November), there was low activity during the day, with one peak between $15.00 \mathrm{~h}$ and $18.00 \mathrm{~h}$. (F. Mramba, personal communication). A study carried out in September 1995 showed that sterile male G. austeni had an activity pattern that was very similar to that of wild insects, i.e. low activity during the day, with a pronounced peak in the afternoon (between $14.00 \mathrm{~h}$ and $18.00 \mathrm{~h}$.) (MJB Vreysen, unpublished data).

Like most tsetse species, G. austeni and G. brevipalpis are markedly diurnal and show pronounced periodicity in their activity. Tsetse activity patterns are known to be under the control of an endogenous clock but in nature, these rhythms are influenced by environmental stimuli such as temperature and light [46]. Circadian rhythm of tsetse flies is a parameter that could have an influence on the sterile male activity in the field, and hence their competitiveness. Whereas the differences in activity patterns of G. austeni observed in the field may be related to different environmental conditions and stimuli, differences observed on the circadian rhythm in the laboratory are more difficult to explain. Crump \& Brady [47] reported only one afternoon peak of spontaneous activity of G. austeni in the absence of any odours or other stimuli. Owaga, Okelo \& Chaudhury [45] however, observed that the U-shaped activity pattern observed in the field 
persisted in the laboratory when the flies were maintained under a $12 \mathrm{~h}$ light; $12 \mathrm{~h}$ dark cycle and stable temperature and humidity conditions. The authors concluded that the activity pattern of $G$. austeni was mainly driven by endogenous factors [45].

The use of field cages to assess mating performance and mating competitiveness of important insect pests in the context of the SIT has gained considerably in importance in the last decade. Whereas originally mainly used for several species of fruit flies, its use has been expanded to other insect groups such as tsetse flies [48] and Lepidoptera [25]. Walk-in field cages have proved to be good surrogates for field studies, which are more complex to carry out and more costly. The data obtained from field cage studies are good indicators of the behaviour of reared insects, but these still need to be verified in the wild, where the released insects are competing with wild insects and are exposed to many varying stimuli. It needs to be pointed out that the field cage experiments were conducted in Pretoria which has a different climate as the tsetse infested area in KwaZulu-Natal. The different environmental conditions might have influenced the circadian rhythm, the activity patterns of the flies and the propensity of mating. It was shown in this study that field cages can be used to assess the mating performance of G. brevipalpis and G. austeni with an average propensity of mating above $46 \%$. Although the propensity of mating was lower than what was obtained in similar field cages with G. f. fuscipes and G. p. palpalis [19], the obtained value indicated adequate environmental conditions for the tests. This relative high propensity of mating obtained indicated that the potential interference on the mating behaviour of the flies because of the personnel intervention probably was minimal.

\section{Conclusions}

This study indicated that the age of colonised male G. brevipalpis and G. austeni can influence their mating competiveness. For the implementation of SIT it can be recommend that sterile males of 9 days or older be released. The economic and logistic consequences of this on potential AW-IPM programmes should be taken into consideration.

\section{Competing interests}

The authors declare that they have no competing interests.

\section{Authors' contributions}

Study conception and design: CDB, MV. Acquisition of data: CDB. Analysis and interpretation of data: $\mathrm{CDB}, \mathrm{GV}, \mathrm{MV}$. All authors read and approved the final version of the manuscript.

\section{Acknowledgements}

We thank the Joint FAO/IAEA Division of Nuclear Techniques in Food and Agriculture for financial support, Gratian Mutika for his expert input and technical assistance. Geoffrey Gimonneau and Adly Abd Alla are thanked for their contribution to the data analyses. Also the co-workers in the Parasites,
Vectors and Vector-borne Diseases Programme of ARC-OVI as well as ARC-OVI facilities for their assistance. We want to thank Dr Kerstin Junker for constructive comments on earlier drafts of this manuscript and the anonymous referees for their valuable input for improving the quality of this manuscript.

\section{Author details}

${ }^{1}$ Agricultural Research Council-Onderstepoort Veterinary Institute Parasites, Vectors \& Vector-borne Diseases, Private Bag X 05, Onderstepoort 0110, South Africa. ${ }^{2}$ Department of Zoology and Entomology, Faculty of Natural and Agricultural Sciences, University of the Free State, PO Box 339, Bloemfontein 9300, South Africa. ${ }^{3}$ Joint FAO/IAEA Division of Nuclear Techniques in Food and Agriculture, Insect Pest Control Laboratory, PO Box 100A-1400 Vienna, Austria.

Received: 27 May 2015 Accepted: 4 September 2015

Published online: 17 September 2015

\section{References}

1. Leak SAG. Tsetse biology and ecology. Their role in the epidemiology and control of trypanosomosis. UK: CABI Publishing; 1999.

2. Esterhuizen J, Kappmeier K, Marcotty T, Van den Bossche P. Abundance and distribution of the tsetse flies, Glossina austeniand G. brevipalpis, in different habitats in South Africa. Med Vet Entomol. 2005;19:367-71.

3. Kappmeier Green K, Potgieter FT, Vreysen MJB. A strategy for an area-wide control campaign with an SIT-(Glossina austeni and Glossina brevipalpis) free South Africa. In: Vreysen MJB, Robinson AS, Hendrichs J, editors. Area-wide control of insect pests. Vienna: Springer; 2007. p. 308-23.

4. Motloang M, Masumu J, Mans B, Van den Bossche P, Latif A. Vector competence of Glossina austeni and Glossina brevipalpis for Trypanosoma congolense in KwaZulu-Natal, South Africa. Onderstepoort J Vet Res. 2012;79:1-6.

5. Van den Bossche P, Esterhuizen J, Nkuna R, Matjila T, Penzhorn B, Geerts S, et al. An update of the bovine trypanosomosis situation at the edge of Hluhluwe-Imfolozi Park, Kwazulu-Natal Province, South Africa. Onderstepoort J Vet Res. 2006;73:77-9.

6. Kappmeier Green K. Strategy for monitoring and sustainable integrated control or eradication of Glossina brevipalpis and G. austeni (Diptera: Glossinidae) in South Africa. PhD thesis, Faculty of Natural and Agricultural Science, University of Pretoria. 2002.

7. Kappmeier K, Nevill EM, Bagnall RJ. Review of tsetse flies and trypanosomosis in South Africa. Onderstepoort J Vet Res. 1998;65:195-203.

8. Moloo SK. The distribution of Glossina species in Africa and their natural hosts. Inter J Trop Ins Sci. 1993;14:511-27.

9. Saini RK, Simarro PP. Tsetse survey in Swaziland. Report to the World Health Organization. 2008. http://www.who.int/trypanosomiasis_african/resources/ The_HAT_atlas.pdf. Accessed Jan 2015.

10. Sigauque I, Van den Bossche P, Moiana M, Jamal S, Neves L. The distribution of tsetse (Diptera: Glossinidae) and bovine trypanosomosis in the Matutuine District, Maputo Province, Mozambique. Onderstepoort J Vet Res. 2000;67:167-72.

11. Vreysen MJB, Robinson AS, Hendrichs J. Area-wide control of insect pests, from research to field implementation. Dordrecht, The Netherlands: Springer; 2007.

12. Vreysen MJB, Saleh KM, Ali MY, Abdulla AM, Zhu Z, Juma KG, et al. Glossina austeni (Diptera: Glossinidae) eradicated on the Island of Unguja, Zanzibar, using the sterile insect technique. J Econ Entomol. 2000:93:123-35.

13. Van der Vloedt AMV, Klassen W. The development and application of the sterile insect technique (SIT) for New World screwworm eradication. FAO; World Animal Review, Italy. World Animal Review (FAO); Revue Mondiale de Zootechnie (FAO); Revista Mundial de Zootecnia (FAO). 1991.

14. Knipling EF. Possibilities of insect control or eradication through the use of sexually sterile males. J Econ Entomol. 1955;8:459-69.

15. Buxton PA. The natural history of tsetse flies. London H.K: Lewis; 1955.

16. Dyck VA, Hendrichs J, Robinson AS. Sterile insect technique: principles and practice in area-wide integrated pest management. Dordrecht, The Netherlands: Springer; 2005.

17. Vreysen MJB. Monitoring sterile and wild insects in area-wide integrated pest management programmes. In: Dyck VA, Hendrichs J, Robinson AS, editors. Sterile insect technique: principles and practice in area-wide integrated pest management. Dordrecht, The Netherlands: Springer; 2005. 
18. Vreysen MJB, Saleh KM, Lancelot R, Bouyer J. Factory tsetse flies must behave like wild flies: a prerequisite for the sterile insect technique. PLoS Negl Trop Dis. 2011.

19. Abila PP, Kiendrebeogo M, Mutika GN, Parker AG, Robinson AS. The effect of age on the mating competitiveness of male Glossina fuscipes fuscipes and G. palpalis palpalis. J Insect Sci. 2003:3:13.

20. Olet PA, Opiyo E, Robinson AS. Sexual receptivity and age in Glossina pallidipes Austen (Dipt. Glossinidae). J Appl Entomol. 2002;126:86-91.

21. Mutika GN, Opiyo E, Robinson AS. Assessing mating performance of male Glossina pallidipes (Diptera: Glossinidae) using a walk-in field cage. Bull Entomol Res. 2001;91:281-7.

22. Van der Vloedt AMV, Barnor $\mathrm{H}$. Effects of ionizing radiation on tsetse biology. Their relevance to entomological monitoring during integrated control programmes using the sterile insect technique. Ins Sci App. 1984;5:431-7.

23. Cayol JP, Vilardi J, Rial E, Vera MT. New indices and method to measure the sexual compatibility and mating performance of Ceratitis capitata (Diptera: Tephritidae) laboratory-reared strains under field cage conditions. J Econ Entomol. 1999;92:140-5.

24. Vera MT, Cladera JL, Calcagno G, Vilardi JC, McInnis DO. Remating of wild Ceratitis capitata (Diptera: Tephritidae) females in field cages. Ann Entomol Soc Am. 2003;96:563-70.

25. Taret G, Sevilla M, Wornoayporn V, Islam A, Ahmad S, Caceres C, et al. Mating compatibility among populations of codling moth Cydia pomonella Linnaeus (Lepidoptera: Tortricidae) from different geographic origins. J Appl Entomol. 2010;134:207-15.

26. Feldmann U. Some quality control parameters used in the rearing of tsetse flies. In: Ochieng'-Odero JPR, editor. Proceedings: techniques of insect rearing for the development of integrated pest and vector management strategies, vol. 1. Nairobi: ICIPE Science Press; 1994.

27. Food and Agriculture Organization of the United Nations/International Atomic Energy Agency, (FAO/IAEA). Standard operating procedures for mass rearing tsetse flies, IAEA, Vienna, Austria, 2006. http://www-naweb.iaea.org/nafa/ipc/ public/Tsetse_Rearing_SOP_web.pdf. Accessed Jan 2015.

28. Calkins CO, Webb JC. A cage and support framework for behavioural tests of fruit flies in the field. Fla Entomol. 1983;66:512-4.

29. Nash TAM. The fertilisation of Glossina palpalis in captivity. Bull Entomol Res. 1955;49:357-68.

30. GraphPad Instat version 3.00 for Windows 95/NT, GraphPad Software, San Diego California USA 2003, http://www.graphpad.com/manuals/Instat3/ InStat3.pdf. Accessed Jan 2015.

31. Calkins CO, Parker AG. Sterile insect quality. In: Dyck VA, Hendrichs J, Robinson AS, editors. Sterile insect technique: principles and practice in area-wide integrated pest management. Dordrecht, The Netherlands: Springer; 2005.

32. Simmons G, Carpenter J, Suckling M, Addison M, Dyck A, Vreysen MJB. Improved quality management to enhance the efficacy of the sterile insect technique for lepidopteran pests. J Appl Entomol. 2010;134:261-73.

33. Malele II, Parker AG. Mating age of Glossina austeni Newstead. Acta Trop. 1999;72:319-24.

34. Teal PEA, Pereira R, Segura DF, Haq I, Gomez-Simuta Y, Robinson AS, et al. Methoprene and protein supplements accelerate reproductive development and improve mating success of male tephritid flies. J Appl Entomol. 2013;137:91-8

35. UI Haq I, Caceres C, Hendrichs J, Teal P, Wornoayporn V, Stauffer C, et al. Effects of the juvenile hormone analogue methoprene and dietary protein on male melon fly Bactrocera cucurbitae (Diptera: Tephritidae) mating success. J Insect Physiol. 2010;56:1503-9.

36. UI Haq I, Vreysen MJB, Cacéres C, Shelly TE, Hendrichs J. Methyl eugenol aromatherapy enhances competitiveness of male Bactrocera carambolae Drew \& Hancock (Diptera: Tephritidae) mating competitiveness. J Insect Physiol. 2014;68:1-6.

37. Vreysen MJB, Zhu Z-R, Saleh KM, Ali MY, Shambwana IA. Eradication of Glossina austeni Newstead on Unguja Island: 3. Releasing gamma sterilised flies from light aircraft. In: Animal trypanosomosis: vector and disease control using nuclear techniques. Leiden, The Netherlands: Backhuys; 1999

38. Oladunmade MA, Feldmann U, Takken W, Tenabe SO, Hamann HJ, Onah J, et al. Eradication of Glossina palpalis palpalis (Robineau-Desvoidy) (Diptera: Glossinidae) from Agropastoral land in central Nigeria by means of the sterile insect technique. In: Sterile insect technique for tsetse control and eradication. Proceedings Final Research Coordination Meeting, Vom, Nigeria, 6-10 June, 1988. 1990. p. 5-23. IAEA/RC/319.3/1.
39. Cuisance D, Itard J. Comportement de mâles stériles de Glossina tachinoides Westw. lâchés dans les conditions naturelles -aux environs de fort - Lamy (Tchad) I. transport, lachers, rhythme d'activite, action sur la population sauvage. Rev Elev Med Vet Pays Trop. 1973;26:55-76.

40. Van der Vloedt AMV, Taher M, Tenabe SO. Effect of gamma radiation on the tsetse fly Glossina palpalis palpalis (Rob.-Desv.) (Diptera, Glossinidae) with observations on the reproductive biology. Int J Appl Radiat Isot. 1978;29:713-6.

41. Vreysen MJB, Van der Vloedt AMV. The effect of inter subspecific hybridization and gamma radiation on the reproductive biology of Glossina palpalis palpalis (Robineau-Desvoidy) and Glossina palpalis gambiensis Vanderplank. Ann Soc Belg Med Trop. 1990;70:145-58.

42. Williamson DI, Baumgartner HM, Mtuya AG, Gates DB, Cobb PE, Dame DA. Integration of insect sterility and insecticides for control of Glossina morsitans morsitans (Diptera: Glossinidae) in Tanzania: II. Methods of sterilization, transportation and release of sterilized males. Bull Entomol Res. 1983;73:267-73.

43. Williamson DI, Dame DA, Gates DB, Cobb PE, Bakuli B, Warner PV Integration of insect sterility and insecticides for control of Glossina morsitans morsitans (Diptera: Glossinidae) in Tanzania: V. The impact of sequential releases of sterilized tsetse flies. Bull Entomol Res. 1983:73:391-404.

44. Kappmeier K. Diurnal activity patterns of Glossina brevipalpis and G. austeni (Diptera: Glossinidae) in South Africa, with reference to season and meteorological factors. Onderstepoort J Vet Res. 2000;67:179-89.

45. Owaga MLA, Okelo RO, Chaudhury MFB. Diel activity pattern of the tsetse fly Glossina austeni Newstead (Diptera: Glossinidae) in the field and in the laboratory. Insect Sci Appl. 1993;14:701-5.

46. Brady J, Crump AJ. The control of circadian activity rhythms in tsetse flies: environment or physiological clock? Physiol Entomol. 1978;3:177-90.

47. Crump AJ, Brady J. Circadian activity pattern in three species of tsetse fly: Glossina palpalis, austeni and morsitans. Physiol Entomol. 1970;4:311-8.

48. Mutika GN, Kabore I, Seck MT, Sall B, Bouyer J, Parker AG, et al. Mating performance of Glossina palpalis gambiensis strains from Burkina Faso, Mali, and Senegal. Entomol Exp Appl. 2012;146:177-85.

\section{Submit your next manuscript to BioMed Central and take full advantage of:}

- Convenient online submission

- Thorough peer review

- No space constraints or color figure charges

- Immediate publication on acceptance

- Inclusion in PubMed, CAS, Scopus and Google Scholar

- Research which is freely available for redistribution 